\title{
OBLIQUE WAVE TRANSMISSION THROUGH ROUGH IMPERMEABLE RUBBLE MOUND SUBMERGED BREAWATERS
}

\author{
V. Vanlishout ${ }^{1}$, H.J. Verhagen ${ }^{2}$ and P. Troch $^{3}$
}

\begin{abstract}
There is a growing interest in the application of submerged rubble mound breakwaters as coastal defence structures. As their defensive ability highly depends on the amount of wave energy remaining at their lee side, the accurate prediction of the energy in the lee of such structures is of utmost importance. Past experiments have shown that the behaviour of rough permeable rubble mound structures under oblique wave attack was found to be significantly different from that of smooth impermeable low crested structures. This behavioural difference has led to the research objective of this present study which is to investigate oblique wave transmission by rough impermeable rubble mound submerged breakwaters using 3D physical model tests. This study intentionally uncouples two parameters, being the permeability of the core and the roughness of the breakwater. Analysing the data of this study shows that the permeability of the core has no visible influence on the structure's behaviour with respect to the influence of oblique wave attack. The fully permeable rough rubble mound breakwater behaves analogous to the fully impermeable rough rubble mound breakwater.
\end{abstract}

Keywords: oblique wave transmission; submerged rubble mound breakwaters; physical 3D model

\section{INTRODUCTION}

There is a growing interest in the application of submerged rubble mound breakwaters as coastal defence structures. As their visual intrusion is low, this is often considered as an aesthetic advantage since they safeguard the (natural) landscape. Further, submerged breakwaters often allow for a simple rehabilitation of existing protective structures by reducing the incident wave conditions. In areas of high sediment transportation, the submerged breakwater has the advantage that this transport will not be completely blocked; the area can remain open and sheltered simultaneously. Finally, a submerged breakwater is environmentally friendly because it provides the sheltered areas still with sufficient amounts of flushing water; the quality of the coastal environment is preserved.

As their defensive ability highly depends on the amount of wave energy remaining at their lee side, the accurate prediction of the energy in the lee of such structures is of utmost importance. The total amount of wave energy to be expected behind a breakwater results from diffraction (around the heads of the breakwater) and wave overtopping/transmission (over/through the breakwater). Especially for low crested breakwaters the latter contribution may be considerable especially in those areas where wave energy arriving from diffraction around the heads of the breakwater is small. Considering that the actual wave field acts in all directions and that not all structures are built parallel to the shoreline, the influence of oblique wave attack on the overtopping/transmitted wave energy should be taken into account.

The importance of oblique wave attack has led to the investigations of the European project DELOS (Environmental Design of Low Crested Coastal Defence Structures, 2002), where wave transmission experiments were performed on low crested breakwaters with the goal of studying the influences of wave obliquities on transmitted wave directions, energy and spectral changes. The data was further analysed by Van der Meer et al. (2003) and the results have been incorporated into the latest overtopping design manual EurOtop (2007).

From these experiments and its analysis, the behaviour of rough permeable rubble mound structures was found to be significantly different from that of the smooth impermeable low crested structures:

- The incident wave direction $\beta_{\mathrm{i}}$ reduces by $20 \%$ after encountering a rough permeable rubble mound breakwater where as for smooth impermeable structures; there is no change in wave direction for incident wave angles less than $45^{\circ}$. For incident wave directions larger than $45^{\circ}$, the transmitted wave direction $\beta_{\mathrm{t}}$ remains at $45^{\circ}$.

- $\quad$ For rough permeable rubble mound breakwaters, the transmission coefficient $\mathrm{K}_{\mathrm{t}}$ is unaffected by the angle of wave attack. For smooth impermeable structures, however, the transmission coefficient decreases significantly with increasing incident wave angles.

\footnotetext{
${ }^{1}$ Division Maritime, Royal Haskoning, George Hintzenweg 85, 3009 AM Rotterdam, The Netherlands

${ }^{2}$ Faculty of Civil Engineering and Geosciences, Delft University of Technology, Stevinweg 1, 2628 CN Delft, The Netherlands

${ }^{3}$ Department of Civil Engineering, Ghent University, Technologiepark 904, B-9052, Zwijnaarde (Ghent), Belgium
} 
- The energy shift towards higher frequencies is found to be greater for smooth impermeable structures than for rough permeable breakwaters. There is no significant influence of oblique wave attack on the degree of energy shift.

It is unclear whether it is the roughness or the permeability of the core that determines the behaviour of the structure. For practical engineering circumstances, it is considered desirable to have more insight into the effect of the roughness and the permeability of the core on the behaviour of the structure.

The objective of this research is to gain insight into the reason for the behavioural difference between rough permeable rubble mound breakwaters and smooth impermeable breakwaters by means of 3D physical model experiments. By investigating oblique wave transmission through a rubble mound breakwater with constant roughness and a changeable core, the influences of the roughness from the permeability of the core can be uncoupled.

A full description of this experimental study and analysis of the results is available in the thesis "Oblique wave transmission through rough impermeable rubble mound submerged breakwaters" (Vanlishout 2008).

\section{EXPERIMENTAL SET-UP}

\section{General}

The 3D experiments of DELOS (2002) were conducted in the laboratory at the Aalborg University of Denmark and showed a behavioural difference between permeable rough rubble mound and smooth impermeable breakwaters. As the aim of this study is to gain insight into the reason for this behavioural difference, the experimental set-up of DELOS (2002) will be the basis for the experimental set-up of this study at the Fluid Mechanics Laboratory of the department of Civil Engineering and Geosciences at the Technical University of Delft.

According to Kramer et al. (2005), a survey of the 1248 existing low crested breakwaters in the European Union was conducted to identify the typical ranges of the structural geometries. Herewith, the chosen geometries were scaled by 1:20; leading to appropriate sizes of the models with respect to the size of the available wave basin at Aalborg University $(9.0 \mathrm{~m} \times 12.5 \mathrm{~m} \times 0.9 \mathrm{~m})$. As the wave basin at the Technical University of Delft has the effective horizontal dimensions of $28.6 \mathrm{~m} \times 16.6 \mathrm{~m}$ and a maximum depth of $0.6 \mathrm{~m}$, the scaling of 1:20 will be retained. A general overview of the basin layout is shown in figure 1 and 2, with its different aspects (i.e. beach and sidewalls, wave generator and breakwater).

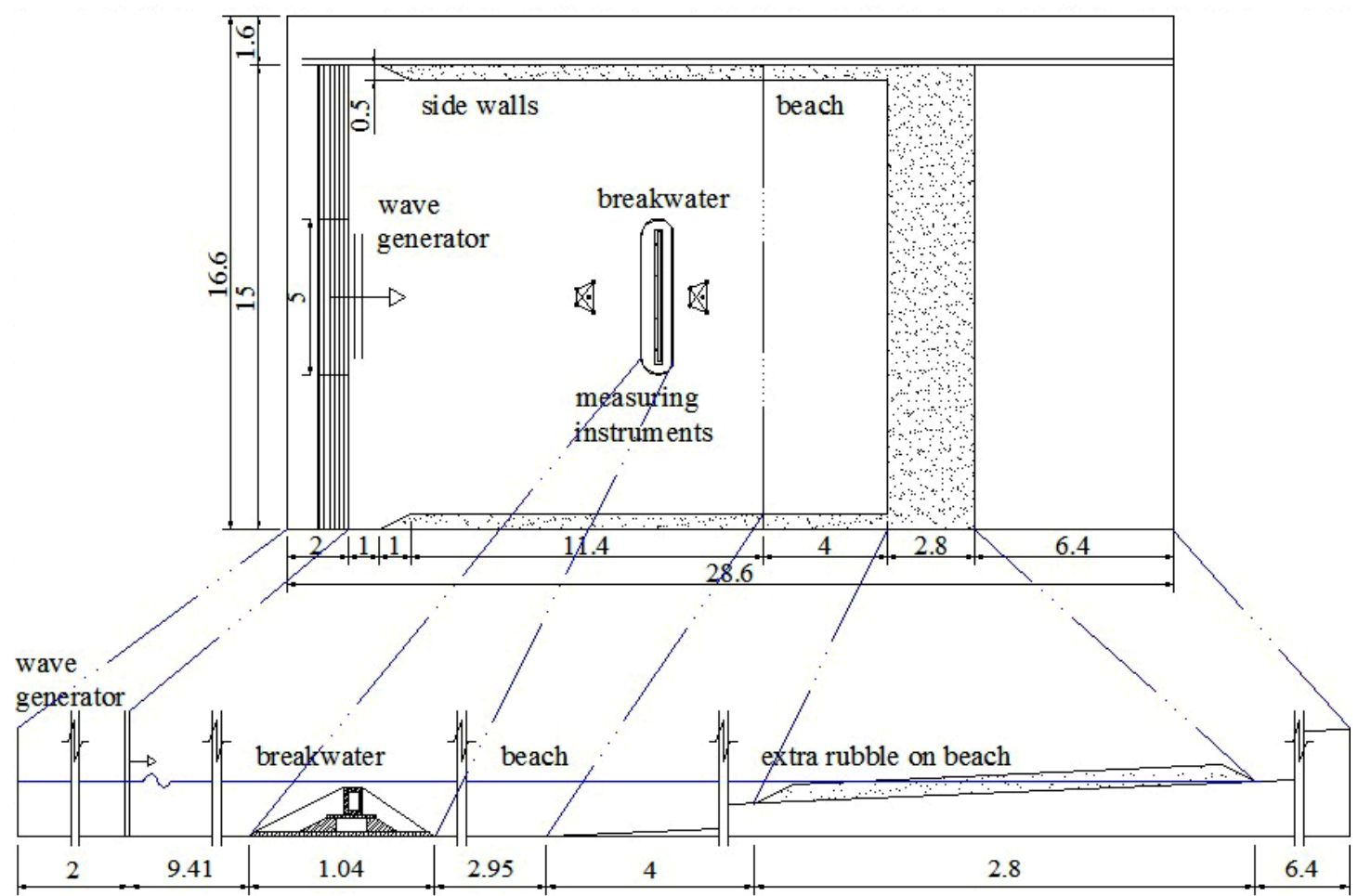

Figure 1. Overview of the wave basin [Dimensions in meters]. 


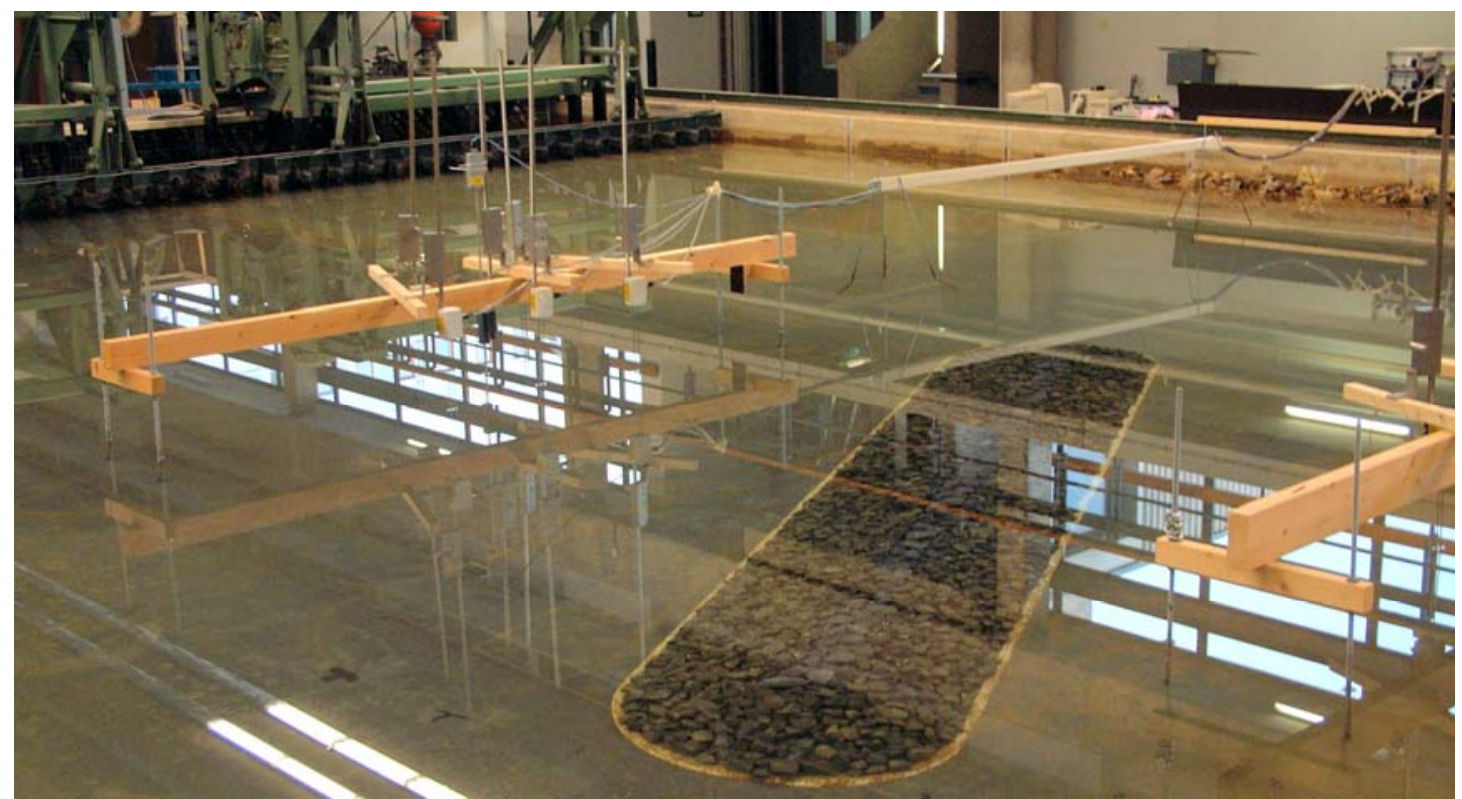

Figure 2. Photograph of wave basin.

Wave basin, beach and side walls

The wave basin has a fixed concrete seabed. Since the experiment should not be affected by the physical constraints of the wave basin, it is essential that the waves travelling towards the side walls and beach are not re-reflected back towards the breakwater. In order to dampen the reflection originating from the sidewalls, a sloping layer of coarse rubble is placed. At the back of the wave basin a sloping (1:30) beach is provided. Where the beach intersects the waterline, an extra layer of coarse rubble is placed to further dampen the waves and to minimize the reflection back towards the breakwater. The influence of the reflected waves on the wave climate at the lee of the breakwater is hereby minimized.

\section{Wave generation}

There are three hydraulic piston-type wave generators placed next to each other, each with a length of five meters and therefore capable of generating irregular waves over the basin width of $15 \mathrm{~m}$. Each generator has one wave board which is driven from one meter above the seabed and has a maximum stroke of $0.26 \mathrm{~m}$. The three generators are synchronized to produce long crested waves, making the wave generation perpendicular to the wave boards (figure 2).

The steering signal for the wave generator is produced by the programme MultiLin version 7.10, a subsection of the Auke software package. It transforms the desired wave condition from the spectral domain to the time domain. The generated series of wave signals is $50 \mathrm{~min}$, with a time-step of $0.01 \mathrm{~s}$ and repeated cyclically.

The wave generators are not equipped with an active reflection compensator, meaning that the generator is not able to minimise re-reflections from the wave board. The wave generator will send waves to the breakwater, which will reflect part of the wave back towards the wave boards. Upon reaching these wave boards, the wave signal will be re-reflected and sent back towards the breakwater. This, on top of the wave generated directly from the wave generator, will result in a wave climate with higher energies than initially accounted for. The target incident wave climate can be simulated correctly by limiting the signal sent to the generator at $90 \%$ capacity.

The standard JONSWAP (JOint North Sea WAve Programme) spectrum is used for all the test series [Holthuijsen (2007)]. More specifically, the transmission response of each breakwater test set-up is investigated under two target wave climates (table 1). This allows for a first wave climate with a lower energy and longer waves. The second wave climate has a higher energy, along with higher, shorter and therefore, steeper waves.

Table 1. Target wave climates.
\begin{tabular}{|l|l|l|l|l|}
\hline Test name & $\mathrm{H}_{\mathrm{i}}[\mathrm{m}]$ & $\mathrm{T}_{\mathrm{p}}[\mathrm{s}]$ & $\mathrm{s}_{\mathrm{op}}[-]$ & $\mathrm{E}[\mathrm{N} / \mathrm{m}]$ \\
\hline Test02 & 0.07 & 1.5 & 0.020 & 3 \\
Test03 & 0.09 & 1.3 & 0.034 & 5 \\
\hline
\end{tabular}




\section{Scale model}

The dimensions of the cross-section (figure 3a) are based on the rubble mound structure of the DELOS (2002) experiments. As the outer dimensions and its roughness need to be kept constant and as the breakwater will be moved during the testing programme, it is decided to fix the armour layer with a polyurethane substance called Elastocoast, which is capable of forming a thin film around the stones without decreasing the permeability of the armour layer. The stones of the armour layer originate from Norway and have a narrow gradation with a $\mathrm{D}_{\mathrm{n} 50}$ of $0.033 \mathrm{~m}$. These conditions allow for the armour layer to remain highly permeable.

The core is made up of an impermeable wooden box available in three different sizes so that in total four different structures can be simulated; ranging from a fully permeable (d) to a fully impermeable (a) rough rubble mound breakwater (figure $3 \mathrm{~b}$ ). The armour stones in the core are not fixed but are consistently used from the same batch and randomly placed in the same manner.

The total length of the breakwater is five meters but is constructed in two parts so that the model can be rotated safely in the basin. The circular roundheads have a variable radius analogous to the cross-section dimensions and prevent the breakwater from ending abruptly. The model is rotated progressively by $15^{\circ}$, ranging from $0^{\circ}$ to $60^{\circ}$, about the centre of the crest width in order to simulate oblique waves. In the extreme orientation of $60^{\circ}$, the breakwater has a remaining perpendicular length of $2.5 \mathrm{~m}$, which is of the same order of magnitude as the longest wave.

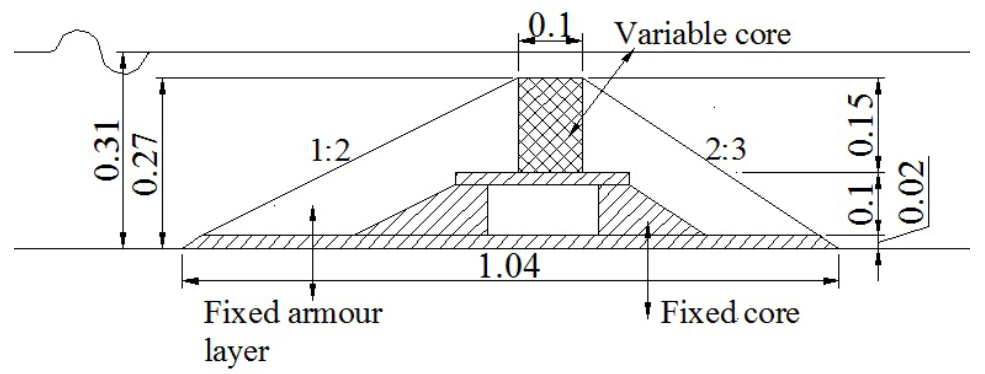

(a) General cross section
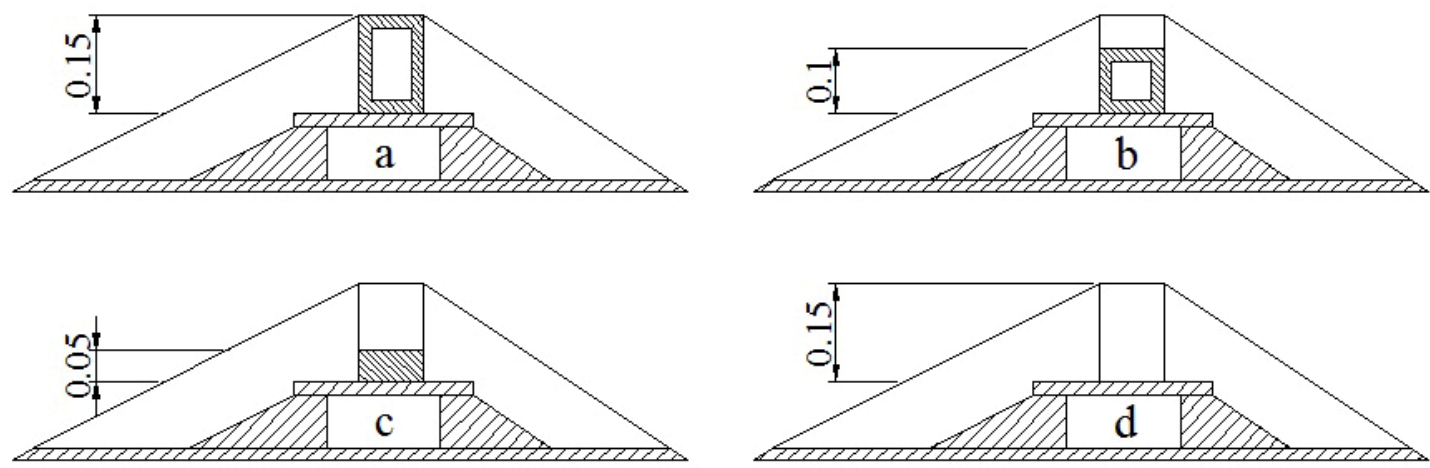

(b) Variable core

Figure 3. Cross-section of the physical model [Dimensions in meters].

\section{DATA ACQUISITION AND ANALYSIS}

Two sets of five resistive wave gauges are used to acquire the data. The relative location of the measuring instruments is based on a non-symmetrical cross sequence so that directional data can be retrieved after signal processing. One set of five wave gauges is placed before the breakwater for the recording of the incident wave conditions while the second set of five wave gauges is placed in the lee of the breakwater for the recording of the transmitted wave conditions.

The signals from the wave gauges are sent to the computer simultaneously. The software package DasyLab 9.0 (Data Acquisition SYstem LABoratory) records the signals to an ASCI file with a sampling frequency of $100 \mathrm{~Hz}$. In order to keep the data manageable, the sampling frequency needs to be as low as possible without allowing the risk of aliasing. As the frequency range of the wave climates is in the order of $0-5 \mathrm{~Hz}$, a sampling frequency of $20 \mathrm{~Hz}$ is sufficient to properly describe the surface elevation without causing a numerical overflow during further analysis. 
The Directional WAve SPectra toolbox version 1.3 (DIWASP) is used for the spectral analysis of the data through calculation algorithms described by Hashimoto (1997) and Pawka (1983). This open source software package is developed by Johnson (2007) at the Centre for Water Research at the University of Western Australia, Perth and is currently distributed and maintained by MetOcean Solutions Ltd, New Zealand.

The build up of DIWASP is relatively simple; it is made up of a collection of Matlab functions, which calculate the directional wave spectra from field data. After the cross power spectra of the discrete time signals are initially calculated, a Fourier analysis translates the data into a three dimensional variance density spectrum by means of the IMLM estimation method (Iterated Maximum Likelihood Method, figure 4). Thereafter, supplementary Matlab functions can be written to calculate the significant wave height, the wave direction and the peak period from the calculated spectrum.

As an intricate analysis of the different methods lies outside the scope of this study, it is sufficient to note that the number of frequency and directional bins for during the analysis is an optimisation choice between resolution, computational speed and accuracy; the best results were found with 512 frequency bins of $0.04 \mathrm{~Hz}, 120$ directional binds of $3^{\circ}$ and 5 iterations. Herewith, for a generated synthetic signal with a significant wave height of $0.070 \mathrm{~m}$, a wave direction of $0^{\circ}$ and a peak period of $1.50 \mathrm{~s}$, the estimation method determines a wave with characteristics of $0.070 \mathrm{~m}, 0^{\circ}$ and $1.51 \mathrm{~s}$ respectively.

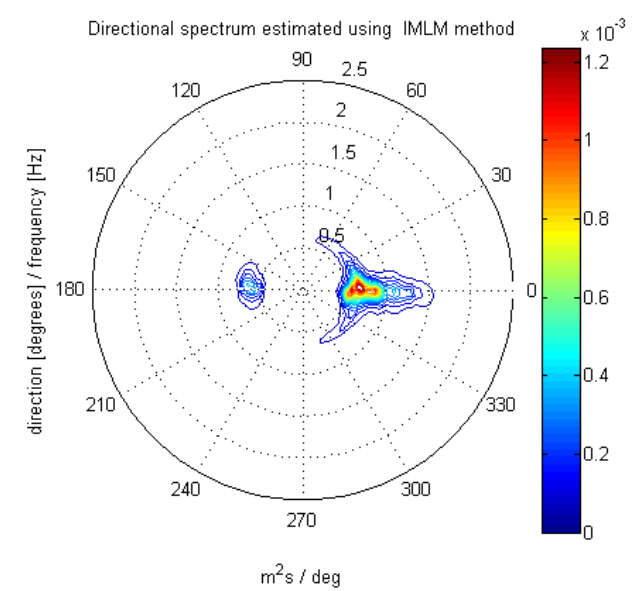

a) Polar plot

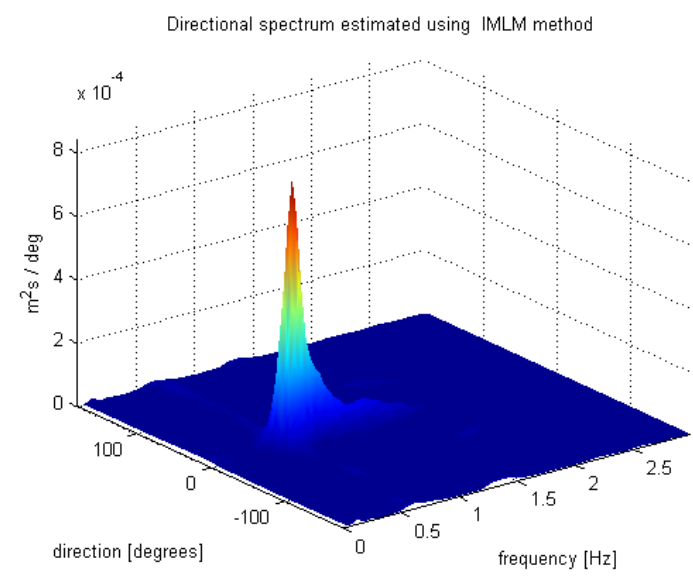

b) Surface plot

Figure 4. Example of 3D spectrum of an incident wave climate $\left(H_{s}=0.07 \mathrm{~m}, \beta_{\mathrm{i}}=0^{\circ}\right.$, fully impermeable core).

\section{SOURCES OF ERROR}

General

There are many sources of error during the testing procedure that could influence the results and decrease the reliability of the data. In the following sections, these are identified and quantified so that the results of the data analysis can be justified.

\section{Sampling length}

The length of the data sample needs to be long enough for two reasons; first to ensure that the incident wave climate resembles that of the target wave climate and second to ensure the reproducibility of the tests. The minimum sampling length during the whole testing procedure of this experiment is $50 \mathrm{~min}$, which corresponds to approximately 2400 waves.

\section{Test sequence without the breakwater}

There are two groups of five wave gauges, from which the data will be compared at later stages. Therefore, it is essential to compare the performance of these two groups relative to each other. Two tests are conducted without the breakwater in the basin in order to calibrate the two groups of five wave gauges with respect to one another. The calculated 'wave transmission coefficient' is 1.08 instead of the theoretical value of 1 . In order to find the reason for this $8 \%$ difference, the variance density spectrum is calculated for each wave gauge individually and compared with one another. From this it is found that there is $12 \%$ more energy in the area at the lee side of the breakwater. This shows that the beach does not fully remove the energy from the waves and reflects that the wave generators 
are not equipped with an active reflection compensator. As a result, a long standing wave develops in the wave basin and causes a slight energy difference between the two locations. As a result, the overestimated transmission coefficient should be reduced during the analysis.

\section{Experimental layout}

The largest source of error lies in the positioning of the breakwater and two groups of wave gauges with respect to the wave generator (i.e. the incident wave direction). There will be an error due to the rotation of the physical model, the placing of the two groups of wave gauges as a whole and the error in the relative positioning of the wave gauges with respect to one another. The first two sources of error will have an effect on the final wave angles calculated. The third error will also have an effect on the significant wave height values because the relative position of the wave gauges is an important input parameter in DIWASP. A total angle of error of $\pm 2.2^{\circ}$ can be accounted for due to the positioning of the breakwater and the instrument groups.

As the individual wave gauges are fixed on a frame, the relative position will not vary during the test procedure. Even though the relative distances can be measured with care, a relative error will become noticeable in DIWASP because the cross-correlation of the various signals is highly dependant on the relative positions of the wave gauges. This can lead to maximum deviations of $3^{\circ}$ wave angles and $0.5 \mathrm{~mm}$ significant wave heights.

\section{Measuring instruments}

Both sets of wave gauges are mounted on a longer frame to minimize the amount of interference from the support legs and to assure that the relative positions of the wave gauges remain constant. In addition, the instruments are placed such that undesired effects such as reflection and diffraction are brought down to a minimum.

\section{Spectral analysis software}

Directional wave spectra software analyse data in the assumption that the waves are short crested wind waves with a high directional spread. Due to the available wave generator, the incident wave climate will mainly be long crested. The directional spread should in theory be infinitely narrow as the waves are only travelling in one direction. The DIWASP software is therefore not intended for such a specific situation; resulting in a directional resolution of $3^{\circ}$ and causing the data to seem organized. However, as the directional error $\left( \pm 2.2^{\circ}\right)$ is of the same magnitude as that of the directional resolution, no improvement will be found by increasing the resolution. Furthermore, the spread of the data is greater for the incident wave direction than for the transmitted wave direction. This reinforces the fact that DIWASP performs better for short crested directional wave climates. The software gives a more stable analysis for the wave climate in the lee of the breakwater than for the incident wave climate.

\section{Additional mound of rubble}

As it is not the aim to observe the influence of diffraction on the wave climate in the lee of the breakwater, an additional permeable mound of rubble is placed alongside the breakwater, consisting of stones originating from the excess supply of armour layer material. The width is approximately $0.40 \mathrm{~m}$ and the height of this additional rubble mound is $0.07 \mathrm{~m}$ lower than the main physical model (figure 5). This is to make sure that the original model stays the dominant source affecting the incident wave climate.

Many small floating wax spheres are randomly placed in the basin so that the surface water currents can be visualised and recorded on video. This visual aid will help to explain qualitatively the effects of placing the additional mound of rubble. Without the additional rubble mound, one observes a relatively fast circulation around the breakwater in the oblique positions of the breakwater. This effect can already be seen at the smallest tested oblique angle $\left(15^{\circ}\right)$. At an oblique layout of $30^{\circ}$, there are also visible diffraction patterns to be seen entering the lee of the breakwater where the instruments are positioned. When the additional rubble mound is placed alongside the breakwater the circulation pattern can be observed to change. The wax spheres no longer travel in large circles but travel in much smaller circles, concentrated at one side of the breakwater at the outer edge (figure 5). The relative speed of the spheres is slower than those during the visual test without the additional rubble mound. It should also be noted that the direction of the current is constant because at the end of each test, a small pile of dirt is accumulated in the centre of the travelled circular path. The diffraction patterns at both ends of the breakwater are no longer very visible; the additional mound of rubble has a positive effect on decreasing the effect of diffraction and breaking the large circulation pattern around the breakwater. Nevertheless, these side effects cannot be considered to be completely negligible. 


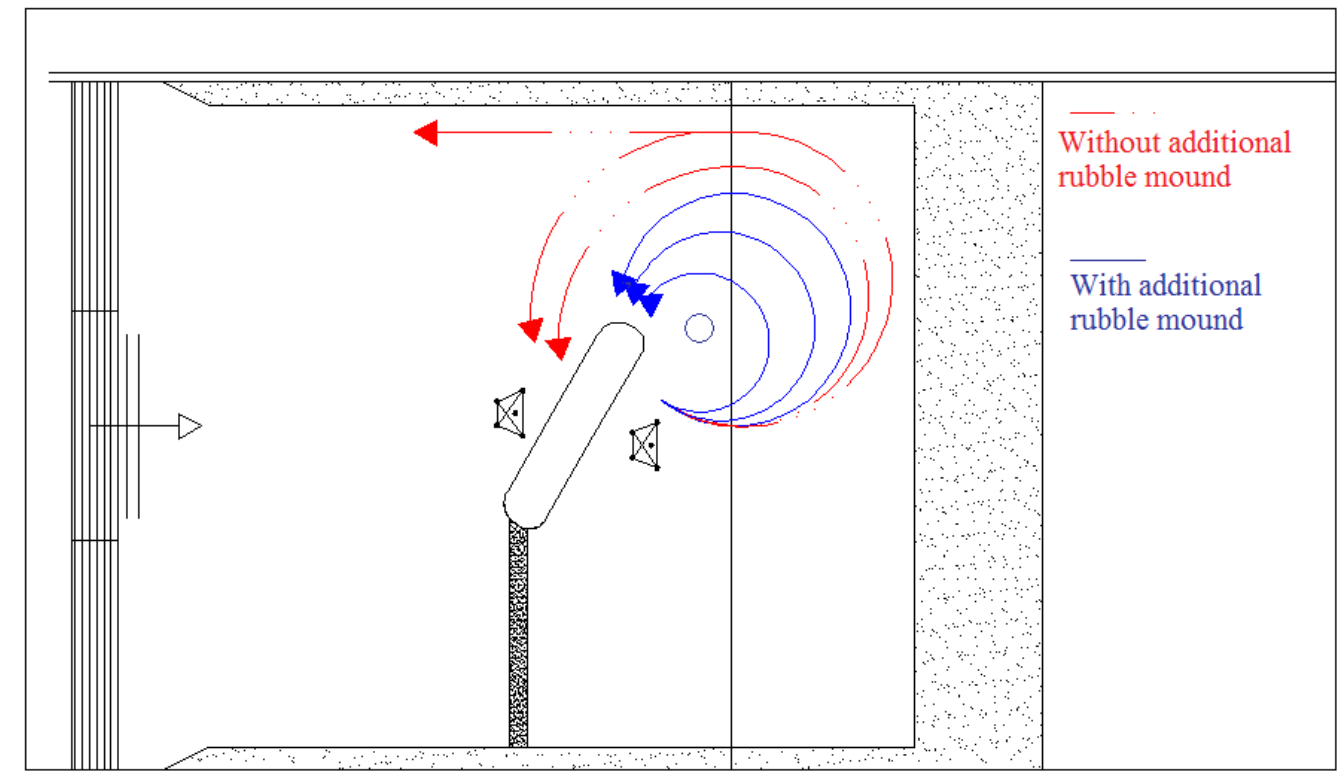

Figure 5. Circulation patterns observed in the wave basin.

\section{RESULTS}

\section{General}

The influence of oblique wave attack on the transmitted wave direction, on the transmission coefficient and on the spectral changes of the transmitted spectrum has been found to be different for rough permeable and smooth impermeable breakwaters [Van der Meer et al. (2003)]. The objective of the present research is to gain insight into the reason for this behavioural difference by experimental means. By varying the permeability of the core and keeping the roughness of the structure constant in this study, these two parameters become uncoupled. Analysing the data of this study allows for the influence of the permeability of the core to be found. When the data of this study is compared with the data of DELOS (2002) and the formulations of Van der Meer et al. (2003, 2005), the observed similarities and discrepancies will allow further insight into this matter.

\section{Transmission coefficient $K_{t}$ with respect to $\mathbf{R}_{\mathrm{c}} / \mathbf{H}_{\mathrm{i}}$}

The transmission coefficient $\mathrm{K}_{\mathrm{t}}$ with respect to the dimensionless factor $\mathrm{R}_{\mathrm{c}} / \mathrm{H}_{\mathrm{i}}$ is shown in figure 6 , where $R_{c}$ is crest freeboard. The empirical relation of d'Angremond et al. (1996), along with the upper and lower limits, is also visualized. The relation is valid for rough permeable rubble mound breakwaters whereas the physical model tested in this study varies from rough permeable to rough impermeable rubble mounds. It can be observed that the data have higher $\mathrm{K}_{\mathrm{t}}$ values than predicted by d'Angremond et al. (1996). However, it has been noted that the transmission coefficient would consistently be overestimated by $8 \%$. When this constant factor is taken into account, one sees that the data fall into the expected limits (figure 6b).

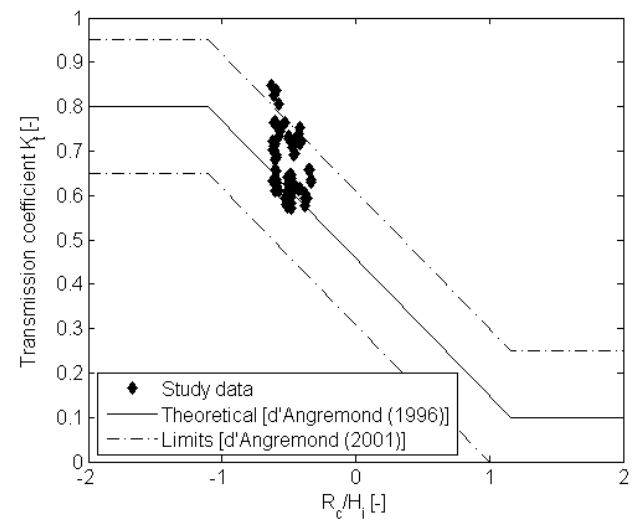

(a) Original study data

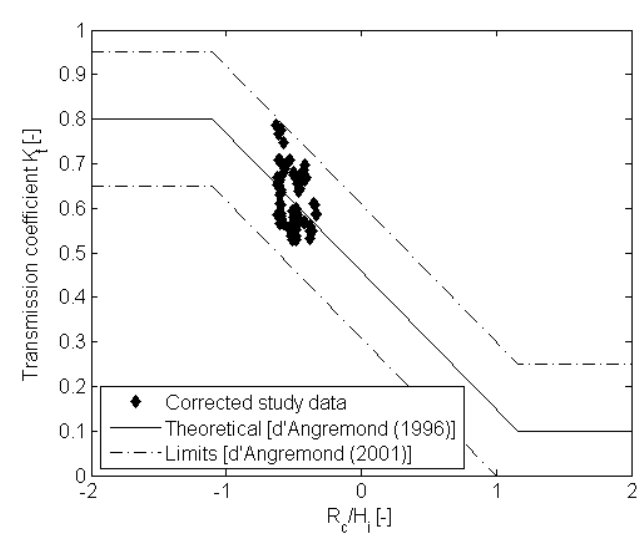

(b) Corrected study data

Figure 6. The transmission coefficient $K_{t}$ with respect to the relative crest height $R_{c} / H_{i}$. 
Change in wave direction: The transmitted wave direction $\beta_{t}$ with respect to the incident wave direction $\beta_{i}$

Based solely on the data of this study, one can observe the following:

- The wave direction remains unchanged or increases by a slight $10 \%$ after encountering the low crested structure (figure 7).

- The permeability of the core shows no significant influence on the change in wave direction with oblique wave attack. The permeable rough rubble mound structure shows the same trend as the impermeable rough rubble mound structure.

- The wave period has no effect on the correlation between the incident and the transmitted wave direction. Relatively longer or shorter waves result in the same change in the wave direction.

- The additional rubble mound does not influence the change in wave direction.

These findings differ from those of Van der Meer et al. (2003), where the rough permeable rubble mound structure shows a reduction of the incident angle of wave attack (figure 7). Although the smooth impermeable structure also shows no significant change in wave direction, this is only observed up to an incident wave angle of $45^{\circ}$. At higher incident angles of wave attack, the transmitted wave direction remains at $45^{\circ}$, which contrasts with the findings of this study. Most important, the data of this study originating from the fully permeable rough rubble mound breakwater do not lie within the scatter of the data originating from the previous study for the analogous permeable rough structure.

The data of this study originate from an experimental programme in which few parameters were varied. Moreover, of the few parameters varied, the range of variation was very limited. Therefore, linear regressions were performed for the data of this study, the rough permeable data of DELOS (2002), the smooth impermeable data of DELOS (2002) and combinations of the three. This allowed the data to be analysed and compared with that of DELOS (2002) in an objective manner. In conclusion, it is recommended to use the following formulations with the respective $95 \%$ confidence bands of the gradients:

$$
\begin{array}{ll}
\text { Rough structures } & \beta_{t}=0.94 \beta_{i} \pm 0.05 \beta_{i} \quad \text { for } \beta_{i} \leq 60^{\circ} \\
\text { Smooth structures } & \beta_{t}=0.94 \beta_{i} \pm 0.05 \beta_{i} \quad \text { for } \beta_{i} \leq 45^{\circ} \\
& \beta_{t}=45^{\circ} \quad \text { for } \beta_{i}>45^{\circ}
\end{array}
$$

It is the roughness of the low crested structure that determines the influence of the incident wave direction on the transmitted wave direction. The behaviour is not influenced by the permeability of the core of the breakwater.

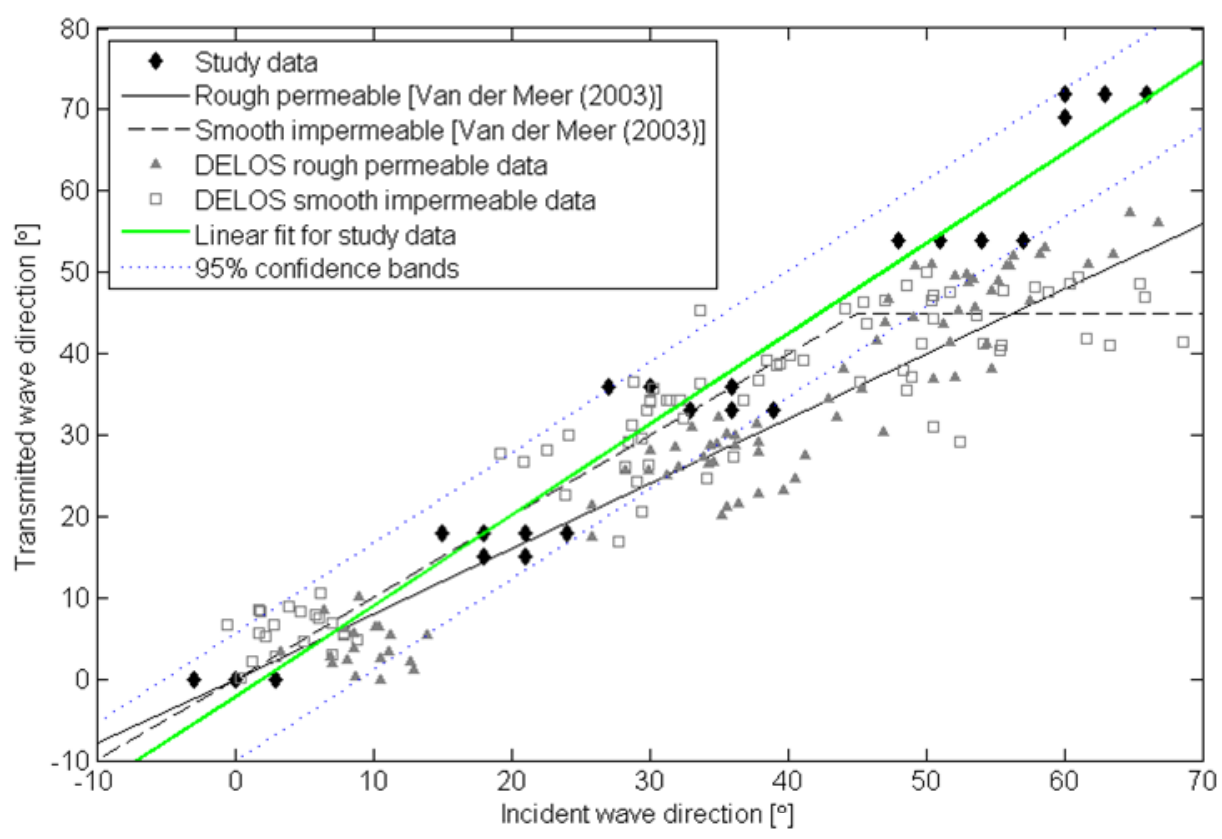

Figure 7. The transmitted wave direction $\beta_{t}$ with respect to the incident wave direction $\beta_{i}$. 
Transmission: The transmission coefficient $K_{t}$ with respect to the incident wave direction $\beta_{i}$ Based solely on the data of this study, one can observe the following:

- The transmission coefficient remains unchanged or increases slightly with increasing incident angle of wave attack (figure 8).

- Within the range of the scatter, the permeability of the core has a negligible influence on the transmission coefficient.

- The incident wave climate with the relatively longer waves and lower spectral energy results in relatively higher transmission coefficients. Furthermore, the incident angle of wave attack has a greater influence on the incident wave climate with the shorter waves; the transmission coefficient increases faster with increasing incident wave direction.

- The additional rubble mound leads to overall higher transmission coefficients. It has no significant influence on the rate at which the transmission coefficient increases with increasing angle of wave attack.

These finding differ from the trend found for smooth impermeable breakwaters [Van der Meer et al. (2003)], where the transmission coefficient decreases with increasing angle of wave attack. On the other hand, the data of this study do lie in the scatter of the data originating from the rough permeable rubble mound of the previous study. After performing linear regressions on the individual data sets as well as the combined sets, it became clear that it is the roughness of the structure that determines the influence of the incident wave direction on the transmission coefficient. Smooth structures are highly influenced by oblique wave attack; the transmission coefficient decreases with increasing angle of wave attack. The transmission coefficient of rough structures, on the other hand, is not dependent on the incident wave direction. Therefore it is recommended to keep using the empirical formulations for the transmission coefficient $\mathrm{K}_{\mathrm{t}}$ of Van der Meer et al. (2005).

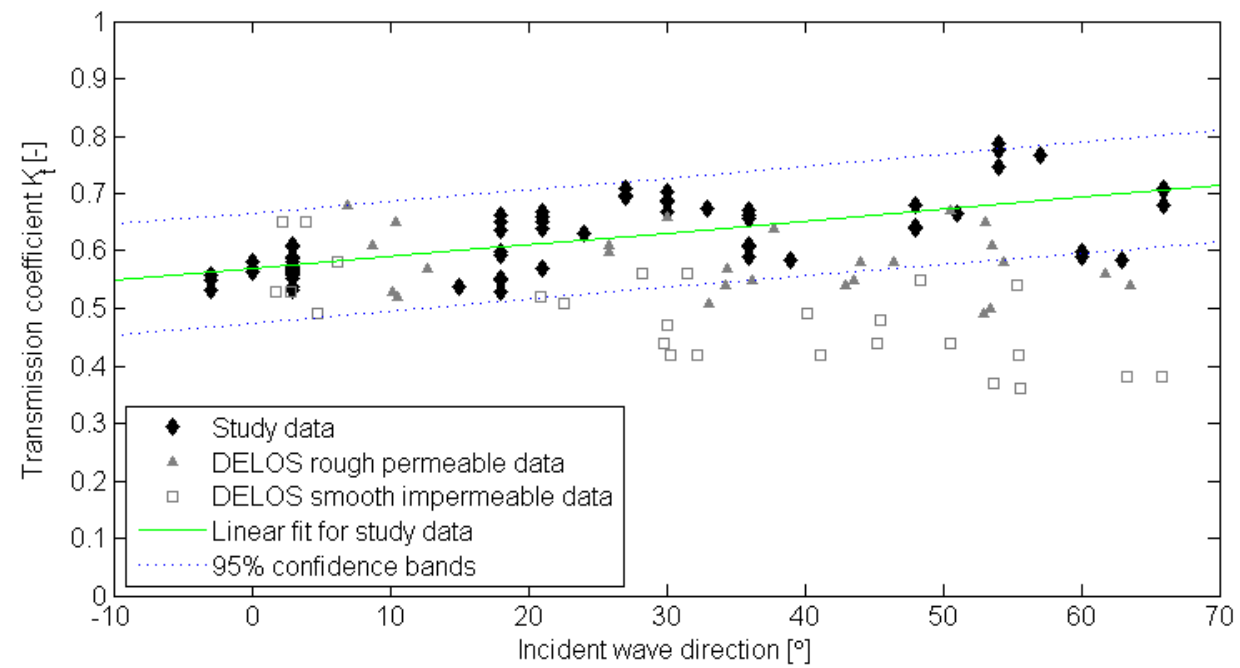

Figure 8. The transmitted coefficient $K_{t}$ with respect to with respect to the incident wave direction $\beta_{i}$.

\section{Spectral changes}

Based solely on the data of this study, one can observe the following:

- The incident wave direction has no significant influence on the percentage of wave energy in the high frequency range of the transmitted spectrum.

- The average percentage of wave energy in the high frequency range of the transmitted spectrum is found to be $33 \%(31-35 \%)$.

- The permeability of the core led to no behavioural differences with respect to the percentage of wave energy in the high frequency range of the transmitted spectrum.

- The longer the waves, the less changes are seen in the shape of the transmitted spectrum. This results in slightly lower percentages of wave energy in the high frequency range.

- The additional mound of rubble has no influence on the spectral changes.

These findings compare well to the observations made by Van der Meer et al. (2005) for rough permeable rubble mound structures. This further supports that the roughness of the structure is the reason for the behavioural differences found by Van der Meer et al. (2005) between smooth impermeable and rough permeable structures. 


\section{CONCLUSIONS}

The framework of the experimental programme of this study allowed four structures to be investigated, ranging from a fully permeable to a fully impermeable rough rubble mound submerged breakwater. The incident angle of wave attack was varied so that its influence on the transmitted wave direction, the transmission coefficient and the transmitted spectrum could be investigated. After validating the acquired data and the spectral analysis software, several conclusions were formed. The experimental set-up of DELOS (2002) was closely followed so that a proper comparison could be made between the results of this study with those formulated by Van der Meer et al. (2003, 2005).

This study intentionally uncoupled two parameters, being the permeability of the core and the roughness of the breakwater. Analysing the data of this study shows that the permeability of the core has no visible influence on the structure's behaviour with respect to the influence of oblique wave attack. The fully permeable rough rubble mound behaves analogous to the fully impermeable rough rubble mound. Thereafter, when comparing the study data with the data of DELOS (2002) and the formulations of Van der Meer et al. (2003, 2005), many similarities and discrepancies are observed. The data of this study compare best with the data of DELOS (2002) and the formulations of Van der Meer et al. $(2003,2005)$ for the rough permeable structure. There is little comparison with the smooth impermeable structure. These findings allow one to suggest that the behavioural difference found by Van der Meer et al. (2003, 2005) may have its roots in the roughness of the structure instead of the permeability of the core. Therefore, it can be concluded that it is the roughness of the structure rather than the permeability of the core that determines the behaviour of the breakwater with respect to the incident wave direction.

\section{REGISTERED TRADEMARKS}

$\begin{array}{ll}\text { DasyLab } & \text { National Instruments, Ireland } \\ \text { Delft-Auke } & \text { WL | Delft Hydraulics } \\ \text { Elastocoast } & \text { Elastogran GmbH, Lemförde, Germany (subsidiary of BASF) } \\ \text { Matlab } & \text { The MathWorks Inc. }\end{array}$

\section{REFERENCES}

d'Angremond, K., Van der Meer, J. W., \& de Jong, R. J. 1996. Wave transmission at low crested structures. Proceedings 25th International Conference on Coastal Engineering.

DELOS. 2002. Wave basin transmission tests: Internal report. http://www.delos.unibo.it/ Docs/Deliverables/D31.pdf. EU Fifth Framework Programme 1998-2002 (Contract EVK3-CT-200000041).

EurOtop. 2007. Wave overtopping of sea defences and related structures: Assessment manual. http:// www.overtopping-manual.com.

Hashimoto, N. 1997. Analysis of the directional wave spectrum from field data. Advances in Coastal and Ocean Engineering. World Scientific Publishing Co. Pte. Ltd., Singapore.

Holthuijsen, L. H. 2007. Waves in Oceanic and Coastal Waters. Cambridge University Press, New York.

Johnson, D. 2007. DIWASP: DIrectional WAve SPectra toolbox version 1.3. http://www.metocean.co.nz/ software. MetOcean Solutions Ltd., New Zealand.

Kramer, M., Zanuttigh, B., Van der Meer, J. W., Vidal, C., \& Gironella, F. X. 2005. Laboratory experiments on low-crested breakwaters. Journal of Coastal Engineering 52.

Pawka, S. S. 1983. Island shadows in wave directional spectra. Journal of Geophysical Research.

Van der Meer, J. W., Wang, B., Wolters, A., Zanuttigh, B., \& Kramer, M. 2003. Oblique wave transmission over low-crested structures. Proceedings Coastal Structures 2003.

Van der Meer, J. W., Briganti, R., Zanuttigh, B., \& Wang, B. 2005. Wave transmission and reflection at low-crested structures: Design formulae, oblique wave attack and spectral change. Journal of Coastal Engineering 52.

Vanlishout, V. 2008. Oblique wave transmission through rough impermeable rubble mound submerged breakwaters. Ghent University. http://repository.tudelft.nl/view/ir/uuid:5c812c5d-b618449c-b26f-06c25e008d7b/

Zanuttigh, B., \& Lamberti, A. 2002. Wave basin hydrodynamic tests: Internal report. http://www.delos.unibo.it/Docs/ Deliverables/D31.pdf. EU Fifth Framework Programme 1998-2002 (Contract EVK3-CT-2000-00041). 